\title{
Tensile and bend behaviour of nanostructured HVOF and flame sprayed stellite coatings
}

\author{
Angelos Koutsomichalis ${ }^{1}$, Michalis Vardavoulias ${ }^{2}$, Antonios Lontos $^{3}$ and Nikolaos \\ Vaxevanidis ${ }^{4, *}$ \\ ${ }^{1}$ Hellenic Air-Force Academy, Laboratory of Materials, TGA 1010, Attica, Greece \\ ${ }^{2}$ Pyrogenesis S.A, Technological Park of Lavrio, GR 195 00, Lavrio, Greece \\ ${ }^{3}$ Frederick University, Dpt. of Mechanical Engineering, Pallouriotissa, 1036, Nicosia, Cyprus \\ ${ }^{4}$ School of Pedagogical and Technological Education, Dpt. of Mechanical Engineering Educators, \\ GR 14121 Heraklion, Athens, Greece
}

\begin{abstract}
Stellite 6 powder (CoCrSiW) was deposited using flame spray (FS) and high velocity oxygen fuel (HVOF) techniques on steel substrates. The microstructure of stellite coatings produced with these deposition techniques displayed a rather similar morphology consisting of cobalt-rich dendrites surrounded by hard $\left(\mathrm{Cr}_{3} \mathrm{C}_{7}\right)$ carbide particles. The stellite (both FS and HVOF) coating was found to reduce the tensile strength of the steel. The failure of the coated steel specimens initiated by cracking on the coating surface, transverse propagation of the cracks towards the coating - substrate interface and diversion along the interface leading to local delamination and breakage. During the bend tests cracks developed along the coating and the main failure in the coating occurred due to the tensile-shear deformation, particularly in the coating-substrate material interface. The coating thickness does not appear to affect the bending strength. During bending the number of surface cracks per unit length decreased with increasing coating thickness. Stereoscopic analysis showed that the thicker the coating the deeper the surface cracks. When the critical stress for crack propagation reached defect sites at the substratecoating interface, the entire coating failed and peeled off from the substrate.
\end{abstract}

\section{Introduction}

The stellite family alloys [(Co-Cr-W $[\mathrm{Ni}, \mathrm{Si}])-\mathrm{C}$ alloys] find numerous applications for wear and corrosion protection [1]. High Velocity Oxygen Fuel (HVOF) technology is usually used to deposit the Stellite coatings. Most of the reports concerning with the HVOF sprayed stellite coatings are focused on coating corrosion and tribological resistance in highly demanding conditions [2-4] while rather limited research has been conducted on

*Corresponding author: vaxev@ aspete.gr 
their mechanical properties [5-8]. In Stellite alloys, Cr provides oxidation and corrosion resistance, as well as strength by the formation of $\mathrm{M}_{7} \mathrm{C}_{3}$ and $\mathrm{M}_{23} \mathrm{C}_{6}$ carbides. Refractory metals such as Mo and $\mathrm{W}$, which have been known to be solid-solution hardening elements also contribute to the strength via precipitation hardening by forming $\mathrm{MC}$ and $\mathrm{M}_{6} \mathrm{C}$ carbides and intermetallic phases such as $\mathrm{Co}_{3}(\mathrm{Mo}, \mathrm{W})$ [9]. Stellite-6 has high hardness at high temperature, high corrosion resistance and wear resistance. Recent research has revealed that some of the properties of the HVOF stellite coatings are related to microstructural features namely the size, morphology and volume fraction of the $\mathrm{Cr}_{7} \mathrm{C}_{3}$ based carbides which depend critically on the cooling rate during solidification [10]. In specific, relevant research has revealed that microstructure plays a major effect on the corrosion resistance of stellite coated systems while the wear behaviour is less influenced by microstructure [11].

In the present study, stellite coatings were deposited by flame spraying and HVOF on steel substrates. Mechanical properties of the coated systems are examined through threepoint bending and tensile tests. Scanning electron microscopy was used to investigate the bend and tensile appearance of the fractured coatings.

\section{Experimental}

Stellite powder CoCrSiW was deposited on the surface of structural steel CK60 specimens. The coating powder characteristics are given in Table 1. Prior to the spraying, the steel substrates were grit blasted by alumina with $0.8-1 \mathrm{~mm}$ grain sizes to achieve mean surface roughness of approximately $\mathrm{R}_{\mathrm{a}}=8 \mu \mathrm{m}$. After sandblasting, samples were cleaned in an ultrasound bath with acetone for 5 min and dried with compressed air. Cleaned samples were vacuum packed and conserved in a dryer at $60{ }^{\circ} \mathrm{C}$ until coating deposition. Powder was heated for two hours in a furnace at $70^{\circ} \mathrm{C}$ prior to spraying, in order to eliminate moisture and optimize flow characteristics.

Table 1. Coating powder characteristic.

\begin{tabular}{|c|c|}
\hline Composition & $\begin{array}{c}\text { Co: } 64.3 \%, \mathrm{Cr}: 28.5 \%, \\
\text { Si: } 1.6 \%, \mathrm{~W}: 4.5 \%\end{array}$ \\
\hline Particle size & $-43+16 \mu \mathrm{m}$ \\
\hline Shape & spheroidal \\
\hline density & $3.3-5.1 \mathrm{~g} / \mathrm{cm}^{3}$ \\
\hline
\end{tabular}

The substrate steel was a $\mathrm{Ck} 40$ grade one; the chemical composition of this steel was $0.60 \%$ wt C, $0.40 \%$ wt Si, $0.75 \%$ wt Mn, $0.035 \%$ wt P and $0.035 \%$ wt S.

The FST M-484.33 Co-based alloy feedstock powder was used for spraying by the Diamond Jet spraying gun (HVOF) and the Metco 3MB gun (flame Spray, FS). The spraying parameters are summarized in Table 2. The thicknesses of the sprayed coatings were ranging from $100 \mu \mathrm{m}$ to $400 \mu \mathrm{m}$.

Table 2. Flame spay and HVOF spraying parameters.

\begin{tabular}{|c|c|c|}
\hline & Flame Spray & \multicolumn{1}{c|}{ HVOF } \\
\hline Pressure (bar) & Oxygen: 1.5 bar & Oxygen: 180 psi, Propane: 80 psi, \\
& Propane: 4.5 bar Air : 5 bar & Airs psi, Argon: 140psi \\
\hline Flow (lt $/ \mathrm{min})$ & Oxygen: 65, Propane: & Oxygen: 265, Propane: 74, Air: \\
& 30, Air: 78 & 353, Argon: 15, coolant: 15 \\
\hline Distance (mm) & 200 & 200 \\
\hline
\end{tabular}




\begin{tabular}{|c|c|c|}
\hline & Flame Spray & HVOF \\
\hline $\begin{array}{c}\text { Meter Wheel speed } \\
(\mathrm{rpm})\end{array}$ & 1000 & 1000 \\
\hline Gun speed $(\mathrm{m} / \mathrm{s})$ & 0,0066 & 0,0042 \\
\hline Flame speed $(\mathrm{m} / \mathrm{s})$ & 45 & 450 \\
\hline Flame temperature $\left({ }^{\circ} \mathrm{K}\right)$ & 3200 & 3000 \\
\hline
\end{tabular}

Two different types of specimens were prepared with the steel substrates: tensile "dog bone" shaped specimens with dimensions $130 \times 100 \times 2.1 \mathrm{~mm}^{3}$ and three point bending specimens with dimensions $131 \times 23 \times 2 \mathrm{~mm}^{3}$. Stellite coating was deposited on both sides of the tensile specimens in equal thicknesses in order to enable balanced loading during tension. Tensile testing was performed in accordance with ASTM E8 standard on an Instron 4482 testing machine using three specimens for each set. Three point bending was accomplished by means of a computer controlled Instron 5544 instrument. The samples were tested in a configuration so as to place the coatings in tension.

Samples were cut with a metallographic saw under continuous lubricant flow, so as to maintain the coatings under compression during cutting. The cross-sections of the samples, for scanning electron microscope (SEM) analysis were obtained by embedding cut specimens in a room temperature-setting epoxy resin. The resins were ground with $\mathrm{SiC}$ abrasive papers having progressively finer abrasive size (400, 800, 1000, $2500 \mathrm{mesh}$ ), and then polished with diamond paste $(3 \mu \mathrm{m})$. The microstructure of the coated samples was observed under a metallographic microscope (Leica DMR) and SEM (Jeol) with image analysis software (Image Pro).

\section{Results and Discussion}

Micrographs in Figure 1 illustrate the cross-sectional microstructure of the stellite FS and HVOF sprayed coatings. The coatings exhibit lamellar structure (typical for sprayed deposits). The coating is built-up by a deposit of lenticular splats, one over the other, in a uniform manner, throughout the coating. The microstructure of Stellite 6 coatings produced with different deposition techniques displays a rather similar microstructure consisting of cobalt-rich dendrites surrounded by hard carbide particles 2, 12]. It can be clearly observed that coatings possess porosity, oxidised, unmelted and semi-melted particles as well as inclusions. Unmelted particles are identified in the coating by their size and near-spherical morphology. Oxide stringers can be observed in the microstructures in the form of intersplat lamellae or globules oriented parallel to the substrate surface. Pores appear black in the micrographs. The percentage of porosity, as measured by image analysis, was $3 \pm 0.5 \%$. No cracks were observed on the sectioned surfaces of the coating. Coatingsubstrate interface exhibited occasional inclusions. 


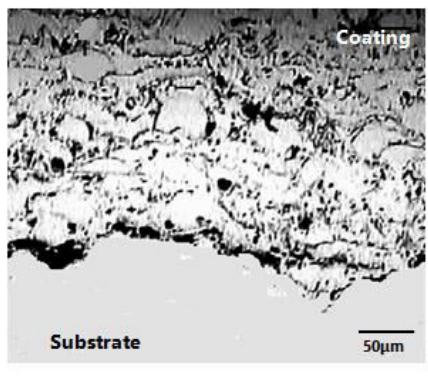

(a)

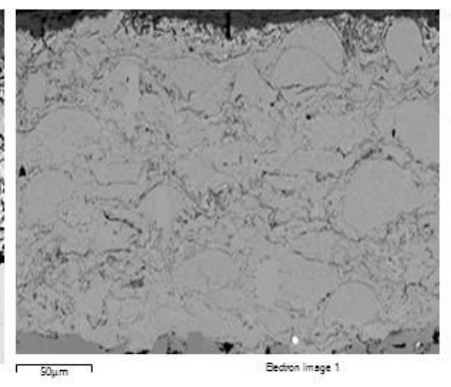

(b)

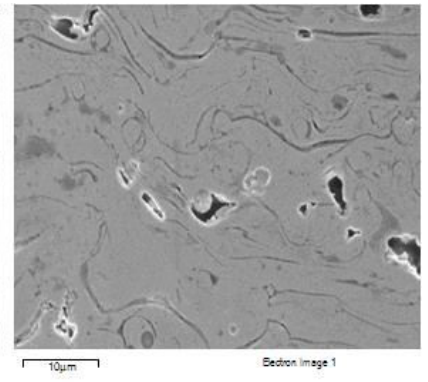

(c)

Fig 1. Cross sections of the stellite coatings (a) optical micrograph of FS coating (b) SEM micrograph of HVOF coating (c) SEM micrograph of FS coating.

Figure 2 shows the engineering stress-strain curves for the deposited $\mathrm{CoCrSiW}$ coating on the steel substrate with various coating thicknesses. The presence of the stellite coating results in a lower tensile strength of the coated steel in comparison with the tensile strength of the uncoated steel. It is evident that with the increase of the coating thickness, independently of the deposition method (HVOF or FS) the tensile strength of the coated system is decreasing. The reduction of the tensile properties can be attributed to the brittle characteristics of the coating, while fracture analysis revealed that brittle cracks, formed in the coating, are the primary cause of the tensile failure of the coated specimens.

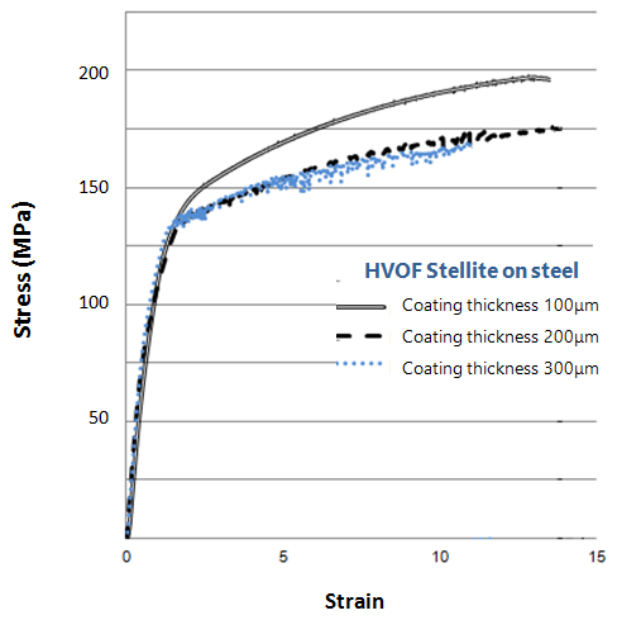

(a)

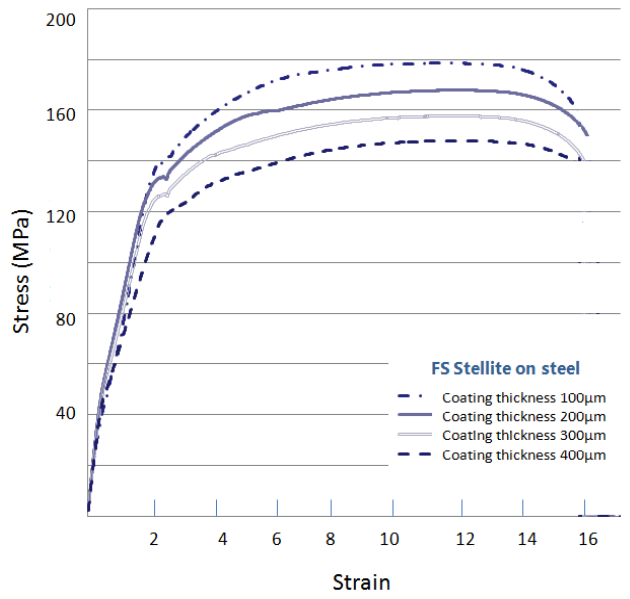

(b)

Fig 2. Stress strain curves of CoCrSiW coated steel with various thicknesses (a) HVOF coated and (b) Flame spray coated.

During tensile tests both HVOF and FS coatings exhibited cracking in the transverse direction of the tensile load due to their brittle nature (figs $3 \mathrm{a}$ and $3 \mathrm{~b}$ ). A cross section of a HVOF sprayed Stellite-steel composite after fracture is illustrated in Fig. 3c. The number of cracks for the HVOF coating was considerably less compared to the FS coating ones presumably due to a less number of pores and internal defaults. The initiation of these cracks was observed at the free surface of the coatings prior to entering the plastic region and can be attributed to the coating brittle nature. By increasing the tensile strain these cracks increased in number and some of them propagated within the coating, in a tree like manner and were either relieved within the coating or stopped at coating-substrate interface 
causing local peeling (fig. 3d). The HVOF stellite coating, though, lasted the tensile loads and was negligibly delaminated while the FS coatings were heavily peeled (fig. 3e). Note also, that the interfacial delamination cracks in coated systems have been already studied; they are attributed to the linkage of previously formed cracks and are both relative to the residual stresses and associated with the fracture toughness of the coating [13-15].

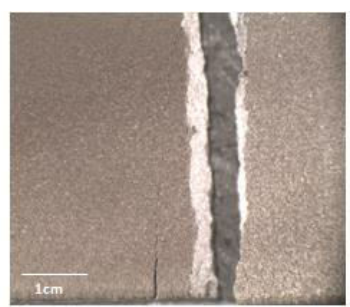

(a)

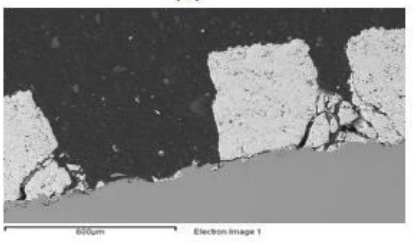

(d)

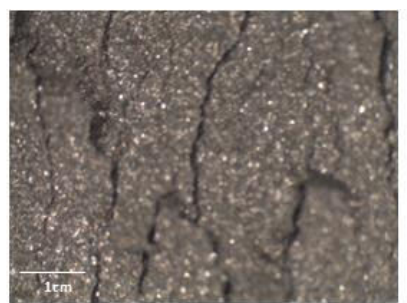

(b)

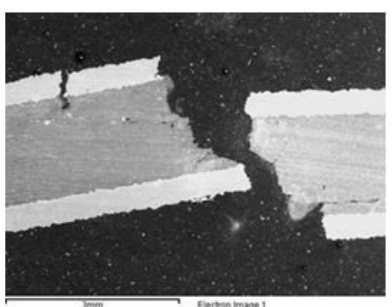

(c)

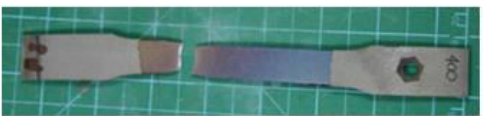

(e)

Fig 3. (a) Plan view of the HVOF stellite coating in the fracture area (b) plan view of the FS stellite coating in the vicinity of fracture (c) SEM cross section of the HVOF stellite on steel after fracture (d) SEM cross section of FS stellite on steel near the fracture area (e) plan view of a fractured and peeled FS stellite coated steel

The coated steel substrate bearing equal CoCrSiW coating thickness on both sides behaves as a laminated composite system stressed parallel to the lamellas with the coating and the substrate being the constituents, which determine the elastic and elastic-plastic behaviour. Figure 4 shows that the elastic modulus of the coated system is decreasing in proportion with the coating thickness (for both types of coatings i.e., FS and HVOF) which could also be explained by the rule of mixtures for layered composites in the elastic region.

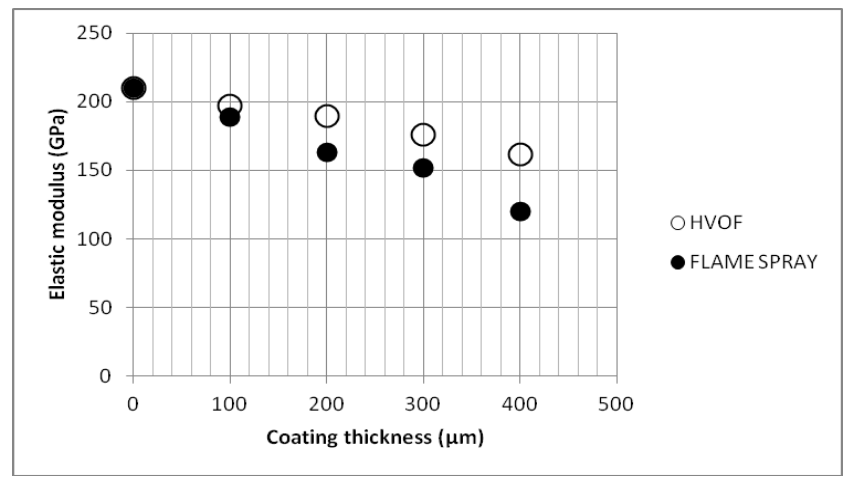

Fig 4. Elastic modulus of the stellite coated steel in relation to coating thickness.

Fig. 5 shows the load-displacement curves for the as received steel and the stellite coated steel both by HVOF (fig. 5a) and flame spray (fig. 5b). It can be seen that the plastic region for the coated specimens initiates at lower load levels for the same flexural 
development which means that the presence of the stellite coating decreases the ductility of the steel substrate especially for the HVOF coatings. Abnormal behaviour in some curves indicates that the gradual deformation of interface of the substrate material probably cannot relieve the stress levels at the interface. The coated steel specimens exhibit similar behaviour regardless of the coating thickness.

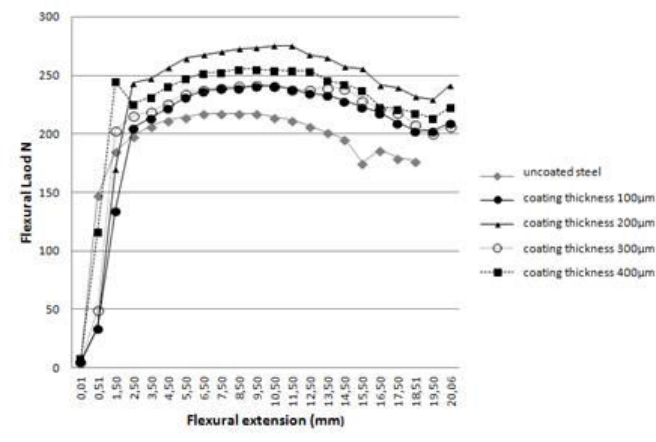

(a)

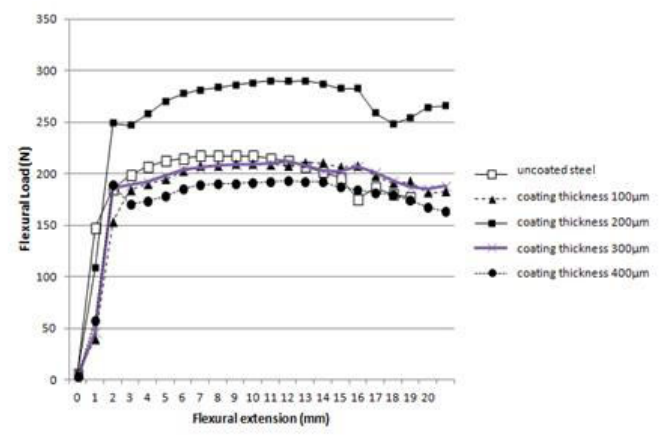

(b)

Fig 5. Load and displacement characteristics after three-point bend tests (a) HVOF coated (b) Flame spray coated.

During bend tests surface cracks were observed; micrographs showing crack formation are presented in Figs 6a-6d. Since the coated surface is placed in the bottom (opposite) site where the three-point bend load is applied, the coating section of the workpiece is subjected to tensile-shear force only. Consequently, the main failure in the coating occurs because of the tensile-shear deformation, particularly coating-substrate material interface; see Fig. $6 \mathrm{~b}$ [16].

The crack in the coating is formed due to the tensile load and initiated at the free surface of the coating as shown in Fig. 6a. It was observed that during bending the number of surface cracks per unit length decreased with increasing coating thickness. Further on, it was also observed that the thicker the coating the deeper the surface cracks. This phenomenon might be attributed to internal stresses, which are primarily developed due to the mismatch between the thermal coefficients of the stellite coating and the steel substrate. In addition, internal stresses can be developed due to tensile-shearing force which creates local stress concentrations at defect sites in the region of coating-substrate interface (such defects might be oxides, unmelted particles etc). It should be noted that stress concentrations at defect sites are, in general, higher than the mean internal stresses. Under the tensile-shear loading delamination occurs above the plastically deformed region. When, therefore, the critical stress for crack propagation is reached in defect sites at the interface, the entire coating fails and peels off from the substrate material (figs $6 \mathrm{c}$ and $6 \mathrm{~d}$ ). When the crack propagation is limited to local region, the fracture of the coating is resulted. In this case, internal stress in the coating is relaxed around the crack sites. If the energy used to propagate the crack is dissipated, the crack cannot extend beyond the substrate material, i.e., it terminates at the free surface of the substrate material.

In the HVOF coating inelastic strain results from micro-cracking and lamellar structure. Since the HVOF coatings can be considered as a superposition of rather weakly bonded layers, the inelastic strain depends on the strain needed for micro-cracks extension and crack deflection within the layers before catastrophic failure [17]. This is a micro-crack 
toughening effect due to the lamellar structure of the coating since the plasma sprayed materials can be considered, in general, as a superposition of weakly bonded tiles.

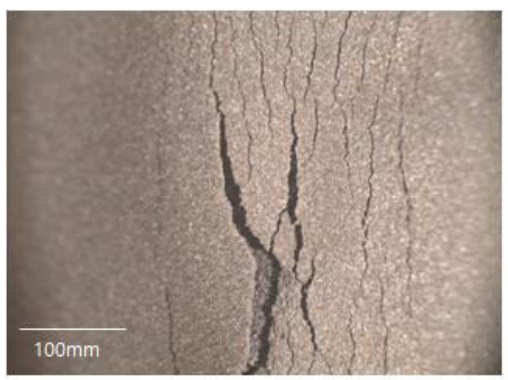

(a)

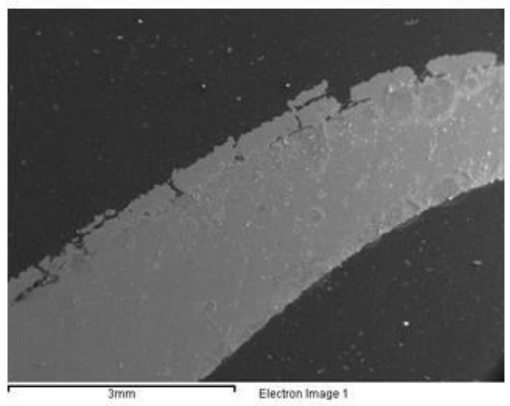

(c)

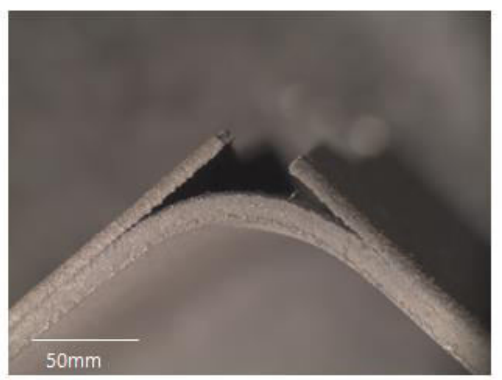

(b)

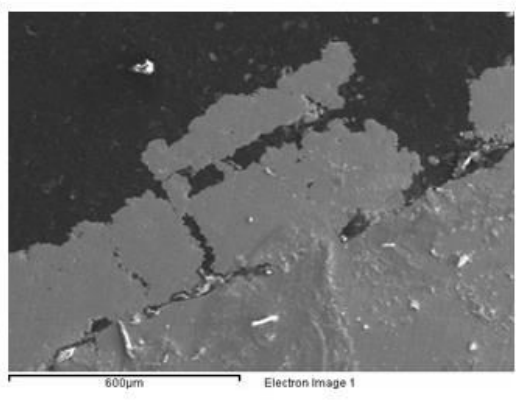

(d)

Fig 6. HVOF stellite coated specimen with thickness $395 \mu \mathrm{m}$ (a) cross section after bending (b) plan view after bending showing local exfoliation (c) cohesive failure area (d) coating exfoliation area.

\section{Conclusions}

1. Stellite CoCrSiW powder was deposited by flame spraying and HVOF on the surface of Ck 60 carbon steel. A typical microstructure characterized by solidified flattened droplets and the coexistence of semi-molten particles with a certain degree of porosity $(3 \pm 0.5 \%$ aprx.) was identified in all cases.

2. Tensile tests were conducted for a number of different coating thicknesses. In all cases examined the tensile strength of the coated steel was lower than that of the uncoated one indicating that the presence of the stellite coating reduces the tensile strength. During tensile loading, cracks first initiated in the outer layer of the coating and transversely propagated towards the substrate, and then cracks multiplied and saturated in the coating; finally interfacial decohesion occurred at the coating - substrate interface.

3. Bend tests confirmed that the presence of the stellite coating decreases the ductility of the steel substrate especially for the HVOF coatings. During bend tests surface cracks were observed. The number of surface cracks per unit length decreased with increasing coating thickness. 


\section{References}

1. S. Houdková, Z. Pala, E. Smazalová, M. Vostřák, Z. Česánek, Surf. Coat. Technol. 318, 129-141 (2017)

2. T.S. Sidhu, S. Prakash, R.D. Agrawal, Surf. Coat. Technol. 201, 1602-1612 (2006)

3. H.S. Sidhu, B.S. Sidhu, S. Prakash, Surf. Coat. Technol. 202, 232-238 (2007)

4. N. Jegadeeswaran, K.U. Bhat, M.R. Ramesh, Int. J. Sci. Eng. Res. 4, 214-220 (2013)

5. A. Kusmoko, D. Dunne, H. Li, HVOF and plasma spraying techniques, Int. J. Curr. Eng. Technol. 4, 32-36 (2014)

6. S. Houdkova, E. Smazalova, Z.Z. Pala, Š. Houdková, E. Smazalová, Z.Z. Pala, J. Therm. Spray Technol. 25, 546-557 (2016)

7. Š. Houdková, Z. Pala, E. Smazalová, M. Vostřák, Z. Česánek, Surf. Coat. Technol. 318, 129-141 (2017)

8. H.S. Sidhu, B.S. Sidhu, S. Prakash, Mater. Sci. Forum 701, 21-29 (2012)

9. T.S. Sidhu, S. Prakash, R.D. Agrawal, Surf. Coat. Technol., 201, 273-281 (2006)

10. G. Kong, D. Zhang, P. D. Brown, D. G. McCartney, S. J. Harris, Mater Sci Technol, 19, 1003-1010 (2003)

11. P. Sassatelli, G. Bolelli, M. Lassinantti Gualtieri, E. Heinonen, M. Honkanen, L. Lusvarghi, T. Manfredini, R. Rigon, M. Vippola, Surf. Coat. Technol., 338, 45-62 (2018)

12. A.H. Dent, A.J. Horlock, D.G. McCartney, S.J. Harris, Surf. Coat. Technol. 139, 244$250(2001)$

13. A. Rabiei, A. Evans, Acta Mater. 48, 3963-3976 (2000)

14. E. Busso, L. Wright, H. Evans, L. McCartney, S. Saunders, S. Osgerby, J. Nunn, Acta Mater, 55, 1491-1503 (2007)

15. S. Catledge, Y. Vohra, S. Woodard, R. Venugopalan, Appl Phys Lett, 82, 1625-1627 (2003)

16. D. Al-Anazi, M.S.J. Hashmia, B.S. Yilbas, J Mater Process Tech., 174, 204-210 (2006)

17. C.K. Lin, S.H. Leigh, C.C. Berndt, R.V. Gansert, S. Sampath, H.Herman, Ceramic Eng. and Sci. Proc., 17, 44-50 (1996) 